\title{
Knowledge, Beliefs and Factors Affecting the Use of Generic Medicines among Patients in Ibb, Yemen: A Mixed-method Study
}

\author{
Yaser Mohammed Al-Worafi ${ }^{1,2}$, Wafa Mohammed Alseragi ${ }^{3}$, Khaled Mohamed Alakhali ${ }^{4}$, Long Chiau Ming ${ }^{5}$, \\ Gamil Othman ${ }^{1}$, Abdulsalam M Halboup ${ }^{1}$, Sultan M. Alshahrani ${ }^{6}$, Sami Mustafa Alshakhshir ${ }^{7}$, Abdulkareem \\ Mohammed Al-Shami ${ }^{8}$, Majid Ali', Mansour Adam ${ }^{10}$, Syed Wajid ${ }^{11}$, Ramadan Mohamed Elkalmi ${ }^{12,13, *}$ \\ ${ }^{1}$ College of Pharmacy, University of Science and Technology, Sana'a, YEMEN. \\ ${ }^{2}$ College of Pharmacy, University of Science and Technology of Fujairah, Fujairah, UAE. \\ ${ }^{3}$ Faculty of Arts, Ibb University, Ibb, YEMEN. \\ ${ }^{4}$ Faculty of Pharmacy, UCSI University, Chera, Kuala Lumpur, MALAYSIA. \\ ${ }_{5}^{5}$ Department Institute of Health Sciences, PAP Rashidah Sa'adatul Bolkiah Institute of Health Sciences, Universiti Brunei \\ Darussalam, Gadong, BRUNEI. \\ ${ }^{6}$ Department of Clinical Pharmacy, College of Pharmacy, King Khalid University, Abha, KSA. \\ ${ }^{7}$ Faculty of Pharmacy, Aqaba University of Technology, Aqaba, JORDAN. \\ ${ }^{8}$ Kulliyyah of Pharmacy, International Islamic University Malaysia, Kuantan, Pahang, MALAYSIA. \\ ${ }^{9}$ College of Pharmacy, Umm Al-Qura University, Mecca, SAUDI ARABIA. \\ ${ }^{10}$ College of Pharmacy, Taibah University, Medina, SAUDI ARABIA. \\ ${ }^{11}$ College of Pharmacy, King Saud University, Riyadh, SAUDI ARABIA. \\ ${ }^{12}$ Dubai College of Pharmacy, Department of clinical Pharmacy and Therapeutics, Dubai, UAE. \\ ${ }^{13}$ Faculty of Medicine, University of Sebha, Sebha, LIBYA.
}

Received: 16 September 2020; Accepted: 28 November 2020

*Correspondence to:

Dr. Ramadan Mohamed Elkalmi, Dubai College of Pharmacy, Muhaisnah, Dubai, United Arab Emirates Phone no: 0097142120337 Email:dr.ramadan@dpc.edu Copyright: (C) the author(s),publisher and licensee Indian Academy of Pharmacists. This is an open-access article distributed under the terms of the Creative Commons Attribution Non-Commercial License, which permits unrestricted non-commercial use, distribution, and reproduction in any medium, provided the original work is properly cited.

\begin{abstract}
Objectives: This study was aimed to explore the knowledge and beliefs of patients in lbb, Yemen, regarding generic medicines and identify factors affecting their use of these medicines. Methods: A mixed qualitative and quantitative study was conducted between Jan 1 and Mar 31, 2017 in lbb, Yemen. A total of 310 patients participated in this study. The questionnaire used for data collection comprised of two sections. The first section covered participants' demographic information and contained six questions addressing patients' ability to differentiate between generic and brand-name medications. The second section comprises 15 items regarding patients' beliefs about generic medicines, answered using a five-point Likert scale. Additionally, seven patients were interviewed using a semi-structured interview guide to explore further the factors affecting their generic medicine use. Results: Only $17.4 \%$ of patients knew the difference between generic and brand-name medicines. Approximately 59 (19\%) patients believed that generic medicines' efficacy was the same as that of brand-name medicines, while 42 (13.5\%) believed that generic medicines took longer to take effect. The vast majority of patients (252) (81.3\%) believed that generic medicines were appropriate for less serious medical conditions. Only 84 patients $(27.1 \%)$ believed that generic medications were the same as brand-name ones. Furthermore, the majority of patients held negative beliefs about generic medicines. The study also found that the price of medicines, physicians' recommendations, and pharmacy dispensers contributed to patients' use of generic medications. Conclusion: This study found that Yemen patients have insufficient knowledge of and negative beliefs about generic medicines. Special oriented and well-designed programs to educate and improve patients and healthcare professionals' understanding and beliefs about generic medicines are urgently needed.
\end{abstract}

Key words: Generic medicine, Knowledge, Beliefs, Brand-name medicine, Yemen.

\section{INTRODUCTION}

The World Health Organization (WHO) defined a generic medicine as "a pharmaceutical product, usually intended to be interchangeable with an innovator product that is manufactured without a license from the innovator company and marketed after the expiry date of the patent or other exclusive rights. ${ }^{\prime[1]}$ However, each country in which generic medicines were introduced to the market has its policy to approve these for the treatment of various conditions. ${ }^{[2]}$ Generally generic medicines are required to be bioequivalent to brand-name medicines; contain the same active ingredients; and have a similar dosage form, dosage strength and route of administration. ${ }^{[2]}$ However, generic medicines may be different to brand-name medicines in color, shape and taste. ${ }^{[2]}$

The price of brand-name medicines is a major barrier to the accessibility of medications to patients in developing countries. ${ }^{[3-5]}$ Generic medicines have the same therapeutic effect but are less expensive than their brand-name 
counterparts and are available in the public and private sectors to treat acute and chronic conditions. ${ }^{[6]}$ The implementation of generic medicines policy can save up to $90 \%$ of total drug expenditure. ${ }^{[7]}$ Consequently, adapting and implementing generic medicine policies is likely to decrease medicine expenditure and contribute to the sustainability of healthcare systems. ${ }^{[5]}$ For this reason and to overcome the challenges of increasing healthcare expenditure as a result of the prescription and dispensation of brand-name medicines, many countries and medical insurance companies globally are implementing policies and strategies to promote the use of generic medicines. ${ }^{[8-10]}$

The Supreme Board of Drugs and Medical Appliances (SBDMA) in Yemen is responsible for regulating medication registration and procurement. It encourages healthcare professionals to recommend generic medicines to assist patients in purchasing their medication at lower prices. ${ }^{[4,11,12]}$ However, patients' acceptance of generic medicine is an essential factor in promoting generic medicine policy as their knowledge of and beliefs about generic medicine is critical to achieving this legislation's goals in any country. ${ }^{[13]}$ There is a lack of studies about patients' knowledge and beliefs towards generic medicines in Yemen; therefore, this study aimed to explore the knowledge and beliefs of patients in Ibb, Yemen, regarding generic medicines as well as to identify the factors affecting their use of these medicines.

\section{MATERIALS AND METHODS}

\section{Study design}

This study was a mixed qualitative and quantitative study conducted between $1^{\text {st }}$ January and March 2017.

\section{Sample size and sampling technique}

The minimum sample size for the quantitative part of the study was estimated to be 370 , convenience sampling was used to recruit the participants.

\section{Participants}

Adult patients were invited to participate in the study when they came to the community pharmacies for buying pharmaceutical products. Paediatric patients were not included in the study.

\section{Study instrument and data collection}

\section{Part I}

The Generic Medicines Scale, adapted from Figueiras et al. (2009), was piloted on 10 patients following backward and forward translation from English to Arabic by qualified linguistic translators and one university lecturer. ${ }^{[14]}$ This questionnaire was self-administered and consisted of two sections. The first section covered participants' demographic data (gender, age, monthly income, education level) and contained six additional questions to explore their ability to differentiate between generic and brand-name medications, including: I ask my doctor questions about my medications? and I know how to differentiate between generic and branded medications?. To facilitate the exploration of patients' ability to differentiate between generic and brandname medications, data collectors asked about the medications that patients themselves used and told them whether these were generic or brand-name medications. The second section contained 15 items addressing the patients' beliefs about generic medications, answered using a five-point Likert scale (Strongly disagree, Disagree, Neutral, Agree, Strongly agree).

\section{Part II}

A convenience sample of seven patients was face-to-face interviewed using a semi-structured interview guide to explore the factors affecting their generic medicine use. The interview guide was validated by three lecturers from the pharmacy practice department, then distributed to four patients for piloting.

\section{Ethical considerations}

This study was approved by the ethics committee of the University of Science and Technology, Yemen. Written informed consent was obtained from the pharmacy managers and patients with respect to their participation in this study. This study was conducted in accordance with the Declaration of Helsinki. Furthermore, no identifiers were used and confidentiality of data was assured by the researchers.

\section{Data analysis}

Data were entered and analyzed using SPSS version 21 (SPSS Statistics for Windows, version 21.0, IBM Corp., USA). Descriptive results were presented as numbers and percentages.

\section{RESULTS}

Out of 420 patients who were invited, 310 agreed to participate in this study, yielding a response rate of $74 \%$. The majority of the respondents were male $(96.8 \%)$ and less than 60 years old $(76.8 \%)$, with a mean age of $42.47 \pm 12.52$ years. Furthermore, the majority of respondents' (81.6\%) monthly income was less than 100 USD and $57.1 \%$ of respondents held a university degree or higher. Table 1 indicates the characteristics of the respondents.

\section{Source of drug information and knowledge about generic medicine}

The results of this study indicate that the majority of the respondents $(n=252)(81.3 \%)$ did not ask physicians or pharmacy dispensers about their medications, whilst only 28 participants $(9 \%)$ asked physicians or pharmacy dispensers about generic alternatives.

\begin{tabular}{|l|l|}
\hline \multicolumn{2}{|l|}{ Table 1: Characteristics of the participants. } \\
\hline Characteristic & $\mathbf{N}=310$ No. (\%) \\
\hline Gender & $300(96.8 \%)$ \\
Male & $10(3.2 \%)$ \\
Female & \\
\hline Age group & $238(76.8 \%)$ \\
$<60$ years old & $72(23.2 \%)$ \\
$\geq 60$ years old & \\
\hline $\begin{array}{l}\text { Monthly income } \\
\text { More than } 100 \text { USD } \\
100 \text { USD or less }\end{array}$ & $57(18.4 \%)$ \\
\hline $\begin{array}{l}\text { Educational level } \\
\text { University degree or higher }\end{array}$ & $253(81.6 \%)$ \\
Secondary education or less & $177(57.1 \%)$ \\
\hline $\begin{array}{l}\text { Ask doctor or pharmacy dispenser about medications } \\
\text { Yes }\end{array}$ & $133(42.9 \%)$ \\
No & $58(18.7 \%)$ \\
\hline $\begin{array}{l}\text { Ask doctor or pharmacy dispenser about generic } \\
\text { medications }\end{array}$ & $252(81.3 \%)$ \\
Yes & \\
No & $28(9 \%)$ \\
\hline $\begin{array}{l}\text { Know how to differentiate between generic and brand- } \\
\text { name medicines } \\
\text { Yes }\end{array}$ & $282(91 \%)$ \\
\hline No & \\
\hline
\end{tabular}




\section{Knowledge of generic medicines}

The majority of the respondents (256) $(82.6 \%)$ did not know how to differentiate between generic and brand-name medicines.

\section{Beliefs about the efficacy of generic medicines}

Table 2 summarizes patients' beliefs about the efficacy of generic medicines.

\section{Beliefs about the similarity of generic medicines to brand-} name medicines

Table 3 summarizes patients' beliefs about the similarity of generic medicines to brand-name medicines.

\section{Factors affecting patients' use of generic medicines}

All patients reported that they purchased their medications based on the lowest price. Only five patients reported that the recommendations of doctors and pharmacists affected their medicine purchasing decisions.

\begin{tabular}{|c|c|c|}
\hline & Belief & $\begin{array}{l}\text { Agree }^{*} \\
\text { No. }(\%)\end{array}$ \\
\hline 1 & $\begin{array}{l}\text { The efficacy of generic medicines is the same as that of brand- } \\
\text { name medicines. }\end{array}$ & $59(19 \%)$ \\
\hline 2 & Generic medicines take longer to take effect. & $42(13.5 \%)$ \\
\hline 3 & Generic medicines are appropriate for less serious conditions. & $252(81.3 \%)$ \\
\hline 4 & $\begin{array}{l}\text { Treatments with generic medicines take longer to resolve the } \\
\text { relevant condition. }\end{array}$ & $42(13.5 \%)$ \\
\hline 5 & Generic medicines are made with lower quality substances. & $159(51.3 \%)$ \\
\hline 6 & Generic antibiotics are less effective than brand-name antibiotics. & $158(51 \%)$ \\
\hline 7 & $\begin{array}{l}\text { Generic medicines have better quality control than brand-name } \\
\text { medicines. }\end{array}$ & $123(39.7 \%)$ \\
\hline 8 & $\begin{array}{l}\text { Generic medicines are less expensive because they are less } \\
\text { effective. }\end{array}$ & $4(1.3 \%)$ \\
\hline 9 & $\begin{array}{l}\text { Generic medicines have the same effect as brand-name } \\
\text { medicines. }\end{array}$ & $94(30.3 \%)$ \\
\hline 10 & $\begin{array}{l}\text { Generic medicines are used to treat the same conditions as } \\
\text { brand-name medicines }\end{array}$ & $94(30.3 \%)$ \\
\hline
\end{tabular}

*Combination of "Strongly Agree" and "Agree"

Table 3: Beliefs about the similarity of generic medicines to brand-name medicines.

\begin{tabular}{|c|l|l|}
\hline & Belief & $\begin{array}{l}\text { Agree* } \\
\text { No. (\%) }\end{array}$ \\
\hline 1 & Generic medicines are the same as brand-name medicines. & $84(27.1 \%)$ \\
\hline 2 & Generic medicines have a similar taste to brand-name medicines. & $97(31.3 \%)$ \\
\hline 3 & $\begin{array}{l}\text { Generic medicines have the same side effects as brand-name } \\
\text { medicines. }\end{array}$ & $86(27.7 \%)$ \\
\hline 4 & $\begin{array}{l}\text { Generic medicines have different packaging to brand-name } \\
\text { medicines. }\end{array}$ & $292(94.2 \%)$ \\
\hline 5 & $\begin{array}{l}\text { The use of generic medicines is similar to that of brand } \\
\text { medicines. }\end{array}$ & $274(88.4 \%)$ \\
\hline
\end{tabular}

${ }^{*}$ Combined Strongly agree and Agree

\section{DISCUSSION}

Healthcare systems in Yemen as well as developing countries consist of public and private sectors and in general, patients need to pay for the treatment and medications in the private isectors. ${ }^{[4,5,15]}$ Therefore, the promotion of generic medicines can lead to substantial savings for both the government and the patients. ${ }^{[1]}$ Hence, patients' knowledge about and ability to differentiate between generic and brand-name medicines are major prerequisites for the widespread use thereof. In view of this, the present study found that only $17.4 \%$ of the participants knew the difference between generic and brandname medicines. This result was lower than that obtained in previous studies done globally. In a United Arab Emirates (UAE) study conducted by Al Ameri et al. ${ }^{[17]} 60 \%$ of consumers had heard of differences between the terms generic medicines and brand-name medicines. Similarly, a study done by Himmel et al. ${ }^{[18]}$ in Germany reported that approximately $63 \%$ of the participants indicated that they were familiar with the terms of generic medicines and brand-name medicines. This difference in findings can be attributed to the differences in healthcare and education levels between countries such as the $\mathrm{UAE}$ and Germany and Yemen. This also suggests that interaction between healthcare professionals and patients about generic medicines is one of the most important factors associated with the use of these medicines.

Moreover, in this study, poor communication was found between healthcare providers and patients. This could be one of the main reasons for patients' disregard for generic medicine and their misconceptions about its effectiveness. In Yemen, both generic and brand-name medicines follow rigorous bioequivalence testing to ensure their compliance with safety standards recommended by United States Pharmacopoeias before they can be marketed. ${ }^{[19]}$ Negative perceptions of generic medicines among the Yemeni population could be due to inadequate knowledge about generic medicines and their active ingredients to make an informed decision about generic medicine substitution. Therefore, communication between patients, physicians and pharmacists could play a major role in promoting the use of generic medicines by better informing the patients. This can strengthen their belief and enhance their knowledge regarding benefits and effectiveness relative to brand-name medicines and, hence, assist in addressing misconceptions about generic medicine substitution.

Although the results obtained in other studies from different countries suggested that participants held strong positive beliefs about generic medicines, only $19 \%$ of the respondents in our study believed that generic medicines were of equivalent quality to brand-name medicines. In Malaysia, Wong et al. ${ }^{[20]}$ conducted a study among outpatients and reported that $53.5 \%$ of the respondents believed that the efficacy of generic medicines was the same as brand-name medicines. In Brazil, more than $70 \%$ of participants accepted that generic medicines were of the same quality as brand-name medicines. ${ }^{[21]}$ Another recent study conducted by Ahire et al. ${ }^{[22]}$ on the general population in different states of India found that almost $61 \%$ of the respondents reported that generic medicines had the same effect as and $39.21 \%$ stated that they adhere to the same FDA guidelines as, brand-name medicines. The low level of belief regarding the efficacy of generic medicine among participants in this study could be due to unfamiliarity with generic medicine policy, limited use of generic medicine, or not having had previous experience with the generic medicine substitution. In fact, a large number of participants in this study as well as those in studies from other countries specifically mentioned several different misconceptions about generic medicine among patients and consumers. ${ }^{[23-26]}$

The results of this study indicated that $27.7 \%$ of the participants believed that generic medicines had the same side effects as brand-name medicines while a previous study conducted by Wong et al. in $2014^{[20]}$ reported a Figure of $44.5 \%$ in this regard. Moreover, the majority of respondents believed 
that generic medicines were appropriate for less serious conditions. These results were similar to those obtained in a previous study conducted in an outpatient pharmacy department in a tertiary care hospital in Malaysia. This suggests that patients may not yet have sufficient confidence to use generic medicines for potentially life-threatening conditions. Half of the respondents believed that generic medicines were made with lower quality substances and approximately $13.5 \%$ of them held the view that treatments with generic medicines take longer. However, as some previous studies have reported that generic medicines were less expensive and lower quality, use is limited to less chronic or serious conditions. ${ }^{[16,18,27]}$ Thus, the misconception that lower price is associated with decreased effectiveness needs to be addressed and corrected. ${ }^{[18,27]}$

In terms of the development of generic products, generic drug formulators should be compelled to follow good manufacturing practice guidelines for the development of generic therapeutic drugs. Similarly, generic product information documents should follow the regulatory submission guidelines which are adopted from skilled regulatory organizations in the United States as well as the International Conference on Harmonization $(\mathrm{ICH}) .{ }^{[28]}$ Furthermore, prior to registration and before the generic substitution begins, generic medicines should undergo rigorous quantitative and qualitative testing to ensure the superiority, safety, efficacy and bioequivalence of the formulated drug. Hence, it is vital to educate patients about regulatory approval and record-keeping systems for generic medicines. ${ }^{[20]}$

\section{CONCLUSION}

The study results revealed that Yemeni participants held negative beliefs about the use of generic medicines, even though many were not aware of the similarities and differences between generic and brand-name medicines. Hence, there is a need for healthcare professionals to provide patients with adequate information about generic medicines. This study was conducted in one Yemini city only which can limit the generalization of its findings. Future studies in other cities are highly recommended to further explore the generic medicines knowledge and perception related factors in order to design the necessary educational interventions.

\section{ACKNOWLEDGEMENT}

We would like to acknowledge all the patients who participated voluntarily in the survey.

\section{CONFLICT OF INTEREST}

The authors declare no conflict of interest.

\section{REFERENCES}

1. World Health Organization. Glossary of Globalization, Trade and Health Terms; 2012. Available from: http://www.who.int/trade/glossary/story034/en.

2. Dunne $S$, Shannon B, Dunne $C$, et al. A review of the differences and similarities between generic drugs and their originator counterparts, including economic benefits associated with usage of generic medicines, using Ireland as a case study. BMC Pharmacol Toxicol. 2013;14(1):1.2.

3. WHO/HAI. Medicine prices, availability, affordability and price components, A synthesis report of medicine price surveys undertaken in selected countries of the World Health Organization Eastern Mediterranean Region. Cairo, World Health Organization Regional Office for the Eastern Mediterranean. 2008. Available from: http://applications.emro.who.int/dsaf/dsa904.pdf. Accessed March , 2016.

4. Al-Worafi YM. Pharmacy practice and its challenges in Yemen. Australas. Medical J. 2014;7(1):17. doi: 10.4066/AMJ.2014.1890
5. Al-Worafi YM. Pharmacy practice in Yemen. In Pharmacy Practice in Developing Countries. 2016;267-87.

6. Sheppard A. Generic medicines: essential contributors to the long-term health of society. IMS Health. 2016. Available from: http://www.imshealth. com/imshealth/ Global/Content/Document/Market_Measurement_TL/ Generic_Medicines_ GA.pdf.

7. King DR, Kanavos P. Encouraging the use of generic medicines: implications for transition economies. Croat Med J. 2002;43(4):462-9.

8. Johnston A, Asmar R, Dahlöf B, et al. Generic and therapeutic substitution: a viewpoint on achieving best practice in Europe. $\mathrm{Br} J$ Clin Pharmacol. 2011;72(5):727-30.

9. Hassali MA, Alrasheedy AA, McLachlan A, Nguyen TA, AL-Tamimi SK, Ibrahim MIM et al. The experiences of implementing generic medicine policy in eight countries: A review and recommendations for a successful promotion of generic medicine use. Saudi Pharmaceutical Journal. Elsevier. 2014. https://doi. org/10.1016/j.jsps.2013.12.017

10. Godman B, Shrank W, Wettermark B, et al. Use of generics-a critical cost containment measure for all healthcare professionals in Europe?. Pharmaceuticals. 2010;3(8):2470-94.

11. Hasan $\mathrm{S}, \mathrm{Al}-\mathrm{Omar} \mathrm{MJ}$, Alzubaidy $\mathrm{H}$, et al. Use of medications in Arab Countries. Handbook of Healthcare in the Arab World. Cham: Springer. 2019;42.

12. Supreme Board of Drugs and Medical Appliances (SBDMA) annual report. 2011. Available from: http://sbd-ye.org/.

13. Dylst $P$, Vulto A, Simoens $S$. Demand-side policies to encourage the use of generic medicines: An overview. Expert Rev Pharm Out. 2013;13(1):59-72.

14. Figueiras MJ, Alves NC, Marcelino D, et al. Assessing lay beliefs about generic medicines: Development of the generic medicines scale. Psychol Health Med. 2009;14(3):311-21.

15. Al-Worafi YM. Drug safety in developing versus developed countries. In Drug Safety in Developing Countries. 2020;613-5.

16. Alrasheedy AA, Hassali MA, Aljadhey $\mathrm{H}$, et al. Is there a need for a formulary of clinically interchangeable medicines to guide generic substitution in Saudi Arabia?. J Young Pharm. 2013;5(2):73-5.

17. AlAmeri M, Mohamed W, Makramalla E, et al. Renal patients' views on generic prescribing and substitution: Example from the United Arab Emirates. East Mediterr Health J. 2013;19(4):373-81.

18. Himmel W, Simmenroth-Nayda A, Niebling W, et al. What do primary care patients think about generic drugs?. Int J Clin Pharmacol Ther. 2005;43(10):472-9.

19. Toklu HZ, Dülger GA, Hıdıroğlu S, Akici A, Yetim A, Gannemoğlu HM, et al. Knowledge and attitudes of the pharmacists, prescribers and patients towards generic drug use in Istanbul-turkey. Pharm Pract. 2012;10(4):199.

20. Wong ZY, Hassali MA, Alrasheedy AA, et al. Patients' beliefs about generic medicines in Malaysia. Pharm Pract. 2014;12(4).

21. Bertoldi AD, Barros AJ, Hallal PC. Generic drugs in Brazil: known by many, used by few. Cadernos De Saúde Pública. 2005;21:1808-15.

22. Ahire K, Shukla M, Gattani M, et al. A survey-based study in current scenario of generic and branded medicines. Int J Pharm Sci. 2013;5(3):705-11.

23. Hassali MA, Kong DCM, Stewart K. Generic medicines: perceptions of consumers in Melbourne, Australia. Int J Pharm Pract. 2005;13(4):257-64.

24. Babar ZUD, Stewart J, Reddy S, et al. An evaluation of consumers' knowledge, perceptions and attitudes regarding generic medicines in Auckland. Pharm World Sci. 2010;32(4):440-8.

25. Shrank WH, Cox ER, Fischer MA, et al. Patients' Perceptions of Generic Medications. Health Aff. 2009;28(2):546-56.

26. Al-Mohamadi A, Halboup AM, Ibrahim Ml, et al. Medical and pharmacy students' perceptions regarding generic medicines in Yemen. J Pharm Pract Comm Med. 2018;4:47-50.Kaplan WA, Ritz LS, Vitello M, et al. Policies to promote use of generic medicines in low and middle income countries: A review of published literature, 2000-2010. Health Policy. 2012;106(3):211-24.

27. Hassali MA, Yuen KH, Ibrahim MIM, et al. Malaysian pharmaceutical industry: Opportunities and challenges. J Generic Med. 2009;6(3):246-52.

Cite this article as: Al-Worafi YM, Alseragi WM, Alakhali KM, Ming LC, Othman G, Halboup AM, et al. Knowledge, Beliefs and Factors Affecting the Use of Generic Medicines among Patients in lbb, Yemen: A Mixed-method Study. J Pharm Pract Community Med. 2020;6(4):53-6. 